\title{
Correction of a vertex encephalocele related to amniotic band syndrome
}

\author{
Aaron M Yengo-Kahn, ${ }^{1}$ Andreas C Plackis, ${ }^{2}$ Christopher M Bonfield, ${ }^{3}$ \\ Srijaya K Reddy (iD ${ }^{4}$
}

${ }^{1}$ Department of Neurological Surgery, Vanderbilt University Medical Center, Nashville,

Tennessee, USA

${ }^{2}$ Department of Anesthesiology, Vanderbilt University Medical Center, Nashville, Tennessee, USA

${ }^{3}$ Department of Neurological Surgery, Division of Pediatric Neurological Surgery, Monroe Carell Junior Children's Hospital at Vanderbilt, Nashville,

Tennessee, USA

${ }^{4}$ Department of Anesthesiology, Division of Pediatric

Anesthesiology, Monroe Carell Junior Children's Hospital at Vanderbilt, Nashville, Tennessee, USA

\section{Correspondence to Dr Srijaya K Reddy; srijaya.k.reddy@vumc.org}

Accepted 19 March 2020

\section{DESCRIPTION}

An encephalocele is a neural tube defect characterised by the displacement of cranial contents outside of the skull. Often, these congenital malformations are due to a primary axial mesodermal defect and occur in $0.8-3.0$ of 10000 live births. ${ }^{12}$ In rare cases, encephaloceles are manifestations of amniotic band syndrome (ABS), best defined as multiple and often-diverse secondary deformities caused by the formation of thin membranous bands in utero. ${ }^{3}$ While encephaloceles related to primary neural tube defects are often found at a midline occipital or frontal location, ABS-related encephaloceles may involve multiple defects with variable locations. ${ }^{12}$ The craniofacial defects associated with ABS usually involve nasal deformity and asymmetry. In contrast to typical encephaloceles, those related to ABS may only be covered with rudimentary meninges rather than true skin. ${ }^{4}$ Correction of the lesion is necessary to allow for more normal brain growth and development, as the presence of the excess tissue may differentially drive cranial skeleton formation. ${ }^{1} 2$ Empiric antibiotic therapy and surgical correction must be undertaken promptly to reduce the risk of infection. ${ }^{2}$ Operative objectives include removal of the herniated cranial contents, closure of the dural defect and closure of the cranial defect, when feasible. Large encephaloceles can present a challenge to the neurosurgeon, especially in terms of positioning and obtaining a watertight dural closure. We present a case of a large atypical vertex encephalocele in a premature neonate with associated complex craniofacial malformations believed to be related to ABS.

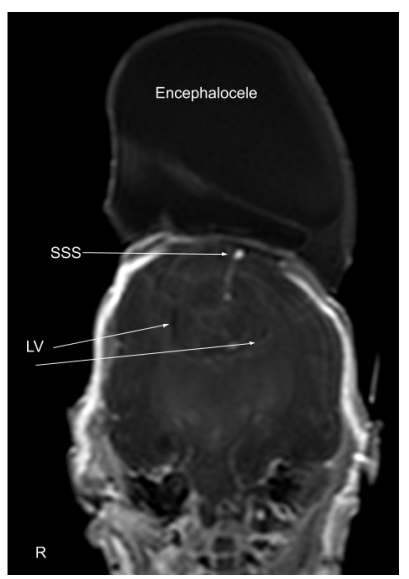

Figure 1 Coronal slice of T1 postcontrast MRI. LV, lateral ventricle; $R$, right side; $S S S$, superior sagittal sinus.

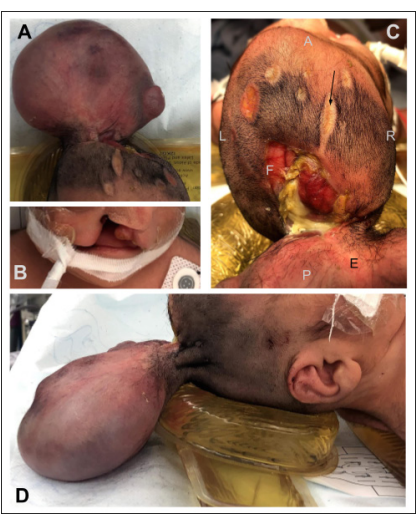

Figure 2 (A) Preoperative image demonstrating vertex encephalocele; (B) associated obliquely oriented cleft palate; (C) close-up view of the preoperative cranial vertex with visible brain covered by arachnoid [F] and numerous abrasions (small arrow) presumably related to amniotic bands; (D) preoperative lateral view demonstrating relative encephalocele size and positioning with a combination of gel rolls to elevate the vertex. A, anterior; E, encephalocele; L, left; P, posterior; R, right.

A $1.9 \mathrm{~kg}$ neonate born at 33 weeks gestation presented for encephalocele repair at 72 hours of life. Preoperative MRI suggested that the superior sagittal sinus remained intracranial and no hydrocephalus was present (figure 1). On examination, an atypical obliquely oriented bilateral cleft palate

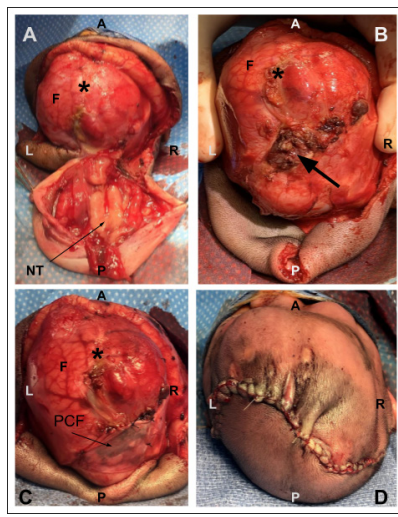

Figure 3 (A) Opened encephalocele with neural tissue; (B) neural tissue truncated, remnants of pedicle visible off midline (thick arrow); (C) pericranial flap, rotated off the occipital bone, closing pedicle defect; (D) skin closure. A, anterior; $\mathrm{F}$, right frontal lobe covered only with arachnoid; $\mathrm{L}$, left; NT, neural tissue; P, posterior; PCF, pericranial flap; $\mathrm{R}$, right. The asterisk (*) denotes midline. 
and a large vertex encephalocele were noted measuring about $10 \mathrm{~cm}$ by $6 \mathrm{~cm}$ (figure $2 \mathrm{~A}, \mathrm{~B}$ ). The lesion was covered with rudimentary skin, although only meninges were present in some areas. The bony defect was notably far larger than the pedicle of the encephalocele (figure 2). Head circumference was $24 \mathrm{~cm}$ $(<3$ rd percentile).

In the operating room, she was positioned supine with head on a small gel donut (figure 2D). After routine induction of anaesthesia and intubation, the patient was positioned and prepped with betadine. Initial dissection was done in the plane between the visible rudimentary meninges and scalp. Once developed, a curvilinear bicoronal incision was made to expose the limited pericranium and cranium anteriorly and laterally. The encephalocele was opened with the fluid contents drained (figure 3A), and the non-functional nervous tissue was truncated with bipolar cautery and scissors at the base of the pedicle (figure 3B). A pericranial flap was rotated from over the superior occipital bone to close the dural defect (figure 3C). No drainage of cerebrospinal fluid was noted. The rudimentary skin and meninges were removed from the encephalocele sac, and the viable appearing skin tissue in the base was rotated for closing the skin (figure 3D). The patient returned to the neonatal intensive

\section{Learning points}

Encephaloceles caused by amniotic band syndrome are rare and more complex than typical encephaloceles, presenting a considerable challenge to the neurosurgical team.

- An MRI of the brain with and without contrast or a CT venogram is critical prior to operating on an encephalocele, especially one in the vertex location, to understand the patient's vascular anatomy.

- Meticulous attention and planning prior to incision are critical to formulating a closure plan for both the skin and dura to minimise the risk of cerebrospinal fluid leak. care unit, was extubated on postoperative day 1 and weaned to room air. Postoperative MRI obtained on postoperative day 3 did not demonstrate any interval development of hydrocephalus. Empiric broad-spectrum antibiotics were continued through postoperative day 3 .

Two months after surgery, her incision had completely healed and she was discharged home, still without evidence of hydrocephalus. However, at her outpatient clinic visit with the neurosurgeon 2 weeks later, it was noted that her encephalocele defect appeared to be larger. Fast-sequence MRI revealed significant dilation of the lateral ventricles, consistent with hydrocephalus. This patient is now scheduled to have a ventriculoperitoneal shunt to treat her hydrocephalus, a common result in patients with encephaloceles.

Contributors AMY-K was involved in the clinical care of the patient, manuscript preparation and editing, obtaining images and approval of the final manuscript. ACP was involved in the clinical care of the patient, manuscript preparation and editing, obtaining images and consent and approval of the final manuscript. CMB was involved in the clinical care of the patient, manuscript preparation and editing, obtaining images and approval of the final manuscript. SKR was involved in the clinical care of the patient, manuscript preparation and editing, obtaining images and approval of the final manuscript.

Funding The authors have not declared a specific grant for this research from any funding agency in the public, commercial or not-for-profit sectors.

Competing interests None declared.

Patient consent for publication Parental/guardian consent obtained.

Provenance and peer review Not commissioned; externally peer reviewed.

ORCID iD

Srijaya K Reddy http://orcid.org/0000-0002-1924-8976

\section{REFERENCES}

1 Lo BWY, Kulkarni AV, Rutka JT, et al. Clinical predictors of developmental outcome in patients with cephaloceles. J Neurosurg Pediatr 2008;2:254-7.

2 Velho V, Naik H, Survashe P, et al. Management strategies of cranial encephaloceles: a neurosurgical challenge. Asian J Neurosurg 2019;14:718-24.

3 Routhu M, Thakkallapelli S, Mohan P, et al. Role of ultrasound in body stalk anomaly and amniotic band syndrome. Int J Reprod Med 2016;2016:1-10.

4 da Silva AJF. Amniotic band syndrome associated with exencephaly: a case report and literature review. J Pediatr Neurosci 2019:14:94-6.

Copyright 2020 BMJ Publishing Group. All rights reserved. For permission to reuse any of this content visit

https://www.bmj.com/company/products-services/rights-and-licensing/permissions/

BMJ Case Report Fellows may re-use this article for personal use and teaching without any further permission.

Become a Fellow of BMJ Case Reports today and you can:

- Submit as many cases as you like

- Enjoy fast sympathetic peer review and rapid publication of accepted articles

- Access all the published articles

- Re-use any of the published material for personal use and teaching without further permission

Customer Service

If you have any further queries about your subscription, please contact our customer services team on +44 (0) 2071111105 or via email at support@bmj.com.

Visit casereports.bmi.com for more articles like this and to become a Fellow 